\title{
Factors Influencing Marginal Bone Loss Around the Dental Implant: A Focus on GBR, Patient Related Factors and Implant Related Factors
}

\author{
Jinseok Lee, Yong-Gun Kim, Jo-Young Suh and Jae-Mok Lee* \\ Department of Periodontology, Kyungpook National University School of Dentistry, \\ Daegu, Korea \\ *Corresponding Author: Jae-Mok Lee, Department of Periodontology, Kyungpook \\ National University School of Dentistry, Daegu, Korea.
}

Received: January 12, 2022

Published: February 17, 2022

(C) All rights are reserved by Jae-Mok Lee., et al.

\section{Abstract}

Purpose of this study was to investigate the marginal bone loss around the implant conducted by the periodontal department of Kyungpook National University Dental Hospital, and to analyze the effect of the patient related factors, implant related factors and practice of Guided bone regeneration. To determine the amount of marginal bone loss around the dental implant, panoramic radiograph at the three stages were compared: Immediately after secondary implant surgery, 1year and 2year after the application of prosthesis. Among the patient-related factors, male suffered greater marginal bone loss around the implant than female after 2 years of follow up period. GBR performed showed greater marginal resorption after 2 years of follow up. Also external type of implant showed less marginal resorption than internal type of implant.

Keywords: Dental Implants; GBR; Marginal Bone Resorption; Patient Factor

\section{Introduction}

Dental Implant is currently one of the treatment options to restore the missing tooth. Prior to the introduction of dental implants procedure, fixed dental restoration or dentures were the only treatment options. However, these treatments require deleting healthy adjacent teeth, which increases the risk of periodontal and pulpal disease [1]. Moreover, bone resorption, which progresses in the edentulous area, cannot be prevented with conventional prosthetic techniques; also, oral hygiene management is difficult in the pontic area. Another conventional treatment option, oral rehabilitation using dentures, significantly decreases masticatory efficiency compared to the natural dentition, and consequently, patient's satisfaction declines significantly due to psychological dissatisfaction [2]. Since the concept of osseointegration introduced by Brännmark in 1969, technology related to implant, including surface characteristic and optimum shape of implant, has been refined over the past 50 years. Currently, the success rate of implants has been improved significantly and is one of the first treatment option to be considered to restore the edentulous area. Compared to the treatment with fixed prosthetics or the denture, the advantages of treatment using implants are distinctive; however unresolved complications still exist [3].

Marginal bone resorption around the dental implant is one of the key factors to consider during the dental implant placement procedure. According to P. Astrand (1996), $1 \mathrm{~mm}$ of physiological bone loss can be observed in the first year after the function of the dental implant, and an annual $0.1 \mathrm{~mm}$ of bone loss is considered as stable implant [4]. Accelerated marginal bone resorption may depict the failing osseointegration, and can be the sign of poor prognosis of the treatment. There are three main causes of marginal bone loss around the dental implant: genetic programming, hormonal activity, and applied load [5] However, according to H.E. Lura, mechanical force within the limits of tolerance actually stimulate the bone apposition by constantly reshaping by its role [6]. 
Furthermore, adequate amount of alveolar bone support is essential prior to dental implant procedure. According to Bränemark, a sufficient amount of alveolar bone is one of the key factors that determine the long-term prognosis of the implant [3]. For the success of the implant, at least $1 \mathrm{~mm}$ or more alveolar bone is required from the implant surface. However, insufficient alveolar bone height is the clinical obstacle that clinician often encounter, and the alveolar bone defect may occur due to the various reasons: trauma, periodontal destruction, and endodontic lesion [7]. If the alveolar bone is insufficient vertically or horizontally, the implant fixture cannot be completely embedded in the alveolar bone and can be served as the source of infection around the dental implant.

To place the dental implant on the defective alveolar bone, proper regenerative procedure is essential. Among the numerous bone augmentation techniques, guided bone regeneration (GBR) is a widely used method and it usually used to overcome the horizontal bone defects. Nyman introduced the concept of guided tissue regeneration which allow osseous regeneration by isolating soft tissue migration [8]. These regenerative concepts developed from bone graft to GBR that uses an absorbable or non-absorbable membrane, which protects the graft material from contamination, and excludes the proliferation of soft tissue cells, and serves as a scaffold for bone apposition in the defective part [9].

Dental implant surface related factors, patient-related factors, and clinician-related factors work in combination as factors that affect implant prognosis. Implant-related elements include the length, diameter, placement position, and surface treatment method of the implant [10]. Patient-related factors include gender [11], smoking status [12], systemic disease, history of periodontal disease, and oral hygiene status. Clinician-related factors include surgical methods and experience of clinician. In order to determine the long-term success and prognosis of the implant, it is necessary to analyze the marginal bone loss around the implant. Therefore, the measurement of the marginal bone height has an important meaning as a method of evaluating the success of the implant $[13,14]$.

The purpose of this study was to investigate the marginal bone loss around the implant conducted by the periodontal department of Kyungpook National University Dental Hospital, and to analyze the effect of the patient's gender, patient's cooperation, type of implant, surface modification of implant, and practice of Guided bone regeneration.

\section{Materials and Methods}

From 2008 to 2013, a retrospective analysis study was conducted using medical records for patients who visited the periodontal department of Kyungpook National University Dental Hospital and underwent implant procedures. A total of 25 patients and $28 \mathrm{im}$ plants were reviewed, and all of the patients were able to perform follow-up for more than 2 years from the date of implantation.

Using the patient's medical records, 1) patient's gender and age distribution 2) patient's cooperation and number of visits 3) the type of implant established and the surface treatment method 4) whether guided bone regeneration was performed.

25 patients were included in this study; 19 were male and 6 were female, ranging from 32 to 79 years old, and the average age was 52. Total of 28 dental implants surgery were included, and the patient group who underwent guided bone regeneration during the first surgery was the experimental group $(n=10)$, and the patient group who underwent only dental implant implantation without bone augmentation was the control group $(n=14)$. If the dental implant was determined that osseointegration is failed, such as uncontrolled inflammation around the implant and was removed due to the severe bone loss, the case was not included. The method of bone augmentation and the type of implant embedded were investigated, and the dental implant surgery with autologous bone transplantation and maxillary sinus graft were not included.

To determine the amount of marginal bone loss around the dental implant, panoramic radiograph at the three stages were compared; initial panoramic radiograph were taken at the second stage of dental implant surgery, panoramic radiograph was taken at the 1 year after applying prostheses, and third radiograph was taken at 2 years after prostheses. The distance was measured by setting the point of dental implant and crown contact as the reference point. The amount of bone resorption was measured at the mesial and distal aspect of implant medium, and the average value was used.

The patient's gender, patient cooperation depicted by the number of visit, characteristics of the implant surface, location, and practice of bone regeneration surgery were set as independent variables, and the amount of marginal bone absorption measured after 1 and 2 years of implant function was set as dependent variables. 
The marginal bone absorption around dental implant according to each factor was statistically tested using the Mann-Whitney test, and the ANOVA test was used for the assessment of the patient's cooperation. All statistical processing used the IBM SPSS Statistics 23 for Windows (SPSS Inc., Illinois, USA) program and found that there was a significant difference below $5 \%$ significance level.

The research protocol of this study was reviewed and approved by the Research Ethics Committee of Kyungpook National University.

\section{Results}

Implant marginal bone resorption according to patient-related factors

Implant marginal bone loss according to gender occurred more significantly when observed for more than 2 years in males, and there was a statistically significant difference between the two groups. ( $\mathrm{P}=0.01)$ There was no statistically significant difference in implant marginal bone loss according to age between patients under 60 years of age and those over 60 years of age (Table 1 ).

\begin{tabular}{|c|c|c|c|c|c|c|}
\hline & & $\begin{array}{l}\text { Implant } \\
\text { Installed }\end{array}$ & $\begin{array}{l}\text { Bone } \\
\text { Loss } \\
(1 \mathrm{yr}) \\
(\mathrm{Mm})\end{array}$ & P-Value & $\begin{array}{l}\text { Bone } \\
\text { Loss } \\
(2 \mathrm{yr}) \\
(\mathrm{Mm})\end{array}$ & P-Value \\
\hline \multirow[t]{2}{*}{ Sex } & Male & 19 & 0.321 & \multirow[t]{2}{*}{0.85} & 1.199 & \multirow[t]{2}{*}{$0.01 *$} \\
\hline & Female & 6 & 0.194 & & 0.309 & \\
\hline \multirow[t]{2}{*}{ Age } & $<60$ & 18 & 0.237 & \multirow[t]{2}{*}{0.08} & 0.991 & \multirow[t]{2}{*}{0.17} \\
\hline & $\geq 60$ & 7 & 0.389 & & 0.891 & \\
\hline
\end{tabular}

Table 1: Implalnt marginal bone loss according to patient-related factors.

* Statistically significant $(\mathrm{P}<0.05)$.

\section{Implant marginal bone loss according to GBR-related factor}

After the observation 1 year after guided bone regeneration, the marginal bone loss was greater in the GBR group, but it was not statistically significant. When $\mathrm{f} / \mathrm{u}$ was performed for more than 2 years, marginal bone loss occurred relatively large in the GBRtreated group, and the difference between the two groups was statistically significant (Table 2).

\begin{tabular}{|l|l|l|l|l|l|}
\hline & $\begin{array}{l}\text { Implant } \\
\text { Installed }\end{array}$ & $\begin{array}{l}\text { Bone } \\
\text { Loss } \\
(\mathbf{1 y r}) \\
\text { (Mm) }\end{array}$ & P-Value & $\begin{array}{l}\text { Bone } \\
\text { Loss } \\
\mathbf{( 2 y r )} \\
\text { (Mm) }\end{array}$ & P-Value \\
\cline { 1 - 3 } GBR & 10 & 0.230 & 0.71 & 1.489 & \multirow{2}{*}{$\mathbf{0 . 0 4} *$} \\
\cline { 1 - 3 } Without GBR & 14 & 0.281 & & 0.486 & \\
\hline
\end{tabular}

Table 2: Implant marginal bone loss according to GBR-related factor.

* Statistically significant $(\mathrm{P}<0.05)$.

Implant marginal bone loss due to implant-related factors

Implant surfaces can be largely classified into RBM and TiUnite, and when after 1 year of follow up period, marginal bone loss occurred more significantly in RBM surface implants; but the difference was not statistically significant, and similar results were shown in the 2 years of observation period. External and Internal types of dental implant, dental implant marginal bone resorption occurred more significantly in the 1 year and 2 years internal type group; however, the statistically significant difference were only shown at the 2 years group (Table 3 and 4 ).

\begin{tabular}{|c|c|c|c|c|c|}
\hline $\begin{array}{l}\text { Implant } \\
\text { Surface }\end{array}$ & $\begin{array}{l}\text { Implant } \\
\text { Installed }\end{array}$ & $\begin{array}{l}\text { Bone } \\
\text { Loss } \\
(1 \mathrm{yr}) \\
(\mathrm{Mm})\end{array}$ & P-Value & $\begin{array}{l}\text { Bone } \\
\text { Loss } \\
(2 \mathrm{yr}) \\
(\mathrm{Mm})\end{array}$ & P-Value \\
\hline RBM & 19 & 0.260 & \multirow{2}{*}{0.88} & 0.640 & \multirow{2}{*}{0.54} \\
\hline Ti-unite & 8 & 0.085 & & 0.620 & \\
\hline $\begin{array}{l}\text { Implant } \\
\text { type }\end{array}$ & $\begin{array}{l}\text { Implant } \\
\text { installed }\end{array}$ & $\begin{array}{c}\text { bone loss } \\
(1 \mathrm{yr}) \\
(\mathrm{mm})\end{array}$ & $\mathrm{p}$-value & $\begin{array}{c}\text { Bone loss } \\
(2 \mathrm{yr}) \\
(\mathrm{mm})\end{array}$ & p-value \\
\hline $\begin{array}{l}\text { Internal } \\
\text { type }\end{array}$ & 21 & 0.380 & \multirow{2}{*}{0.12} & 0.940 & \multirow{2}{*}{$0.01 *$} \\
\hline $\begin{array}{l}\text { External } \\
\text { type }\end{array}$ & 6 & 0.090 & & 0.125 & \\
\hline
\end{tabular}

Table 3: Implant marginal bone loss according to Implant characteristic.

* Statistically significant $(\mathrm{P}<0.05)$. 


\begin{tabular}{|l|l|l|l|l|l|}
\hline $\begin{array}{l}\text { Frequency } \\
\text { Of Visit } \\
\text { (Number/ } \\
\text { Year) }\end{array}$ & $\begin{array}{l}\text { Implant } \\
\text { Installed }\end{array}$ & $\begin{array}{l}\text { Bone } \\
\text { Loss } \\
\mathbf{( 1 y r )} \\
(\mathbf{M m})\end{array}$ & P-Value & $\begin{array}{l}\text { Bone } \\
\text { Loss } \\
\mathbf{( 2 y r )} \\
(\mathbf{M m})\end{array}$ & P-Value \\
\hline Less than 3 & 3 & 0.490 & 0.75 & 1.780 & \multirow{2}{*}{$\mathbf{0 . 0 1} *$} \\
\cline { 1 - 3 } 35 & 15 & 0.304 & & 1.002 & \\
\cline { 1 - 2 } more than 5 & 7 & 0.286 & & 0.993 & \\
\hline
\end{tabular}

Table 4: Implant marginal bone loss according to accommodation of patient.

* Statistically significant $(\mathrm{P}<0.05)$.

Implant marginal bone loss according to patient cooperation

It was classified into three groups according to the number of visits per year of patients. Overall, as the number of patient visits increased, decreased amount of marginal bone resorption was shown, but the difference was not statistically significant.

\section{Discussion}

This study was conducted retrospectively and was a long-term follow-up of patients who visited the periodontal department of Kyungpook National University Dental Hospital from 2008 to 2013. During the observation period, the implant failed in two patients, and the case was excluded from our study.

In this study, among the factors affecting implant prognosis, practice of GBR, patient-related factors, implant-related factors, and patient cooperation were evaluated for marginal bone loss of dental implant. There were factors that showed a statistically significant relationship between the evaluation factor and the survival rate.

First of all, among the patient-related factors, male suffered greater marginal bone loss around the implant than female and there was a statistically significant difference when follow-up period exceeded two years. Greater marginal bone loss in the male group can be related with the strong occlusal force [16]. In addition, there were no smokers in the female group in present study, but about half ( 9 male) were found as smokers. Smokers have a lower long-term survival rate of implants than non-smokers, and the prognosis is also poor, which is considered to have affected in this study [17].

Two materials (MBCP and Bio-oss) were used in bone augmentation techniques. However, in this study, we compared the marginal bone resorption according to the presence or absence of Guided bone regeneration. There was no significant difference in the degree of bone resorption after 1 year of implant placement. However, when follow up period exceeded the 2 years, the mean marginal bone resorption showed the statistically significant difference (1.489 $\mathrm{mm}$ and $0.486 \mathrm{~mm}$ ). Benic (2009) [16] reported that there was no significant difference in marginal bone loss between dental implant with or without GBR [18]. Meanwhile, Bazrafshan and Darby [19] reported that bone loss was significantly lower in the bone graft group as a result of observing bone grafts for 2 to 7 years at the same time during implant placement, contrary to the this study.

Among the implant related factors, the connection type of implant (external or internal type) showed the statistically different outcome; and external type of dental implant was shown as more reliable type than internal type of implant. The data was consistent with the systematic review of Palacios-Garzón [20] that the external implant type gave more promising result than the internal type; while difference between the two type of implant was not significant. Author also implied larger samples and longer follow-up period is needed as our experiment.

\section{Conclusion}

Based on our results, gender, type of implant and GBR procedure may affect the marginal bone resorption around the dental implant. Thus, patient-related factors should be thoroughly analyzed before implant placement, and the clinician should aware that GBR procedure possibly lead to marginal bone loss after the function of dental implant. However, other factors such as the bone quality of the implant site, the type of prosthesis above the implant and the cause of tooth loss can affect the marginal bone resorption of the implant. This study was conducted retrospectively, and the variables affecting the cumulative survival rate are diverse. On the further study, the broad experiment group would be necessary for data that are more consistent.

\section{Bibliography}

1. Carr AB and Laney WR. "Maximum Occlusal Force Levels in Patients With Osseointegrated Oral Implant Prostheses and Patients With Complete Dentures". The International Journal of Oral and Maxillofacial Implants 2.2 (1987): 101-108.

2. Wetherell JD and Smales RJ. "Partial denture failures: a longterm clinical survey”. Journal of Dentistry 8.4 (1980): 333-340. 
3. Brånemark PI., et al. "Intra-osseous anchorage of dental prostheses. I. Experimental studies”. Journal of Plastic Surgery and Hand Surgery 3.2 (1969): 81-100.

4. Astrand P., et al. "Titanium implants and onlay bone graft to the atrophic edentulous maxilla: a 3-year longitudinal study". International Journal of Oral and Maxillofacial Surgery 25.1 (1996): 25-29.

5. Treharne RW. "Review of Wolff's law and its proposed means of operation". Orthopedic Reviews 10 (1981): 35-47.

6. H Lura. "Tissue Reactions of Bone Upon Mechanical Stresses". American Journal of Orthodontics 38.6 (1952): 453-459.

7. Mecall RA and Rosenfeld AL. "Influence of residual ridge resorption patterns on fixture placement and tooth position, Part III: Presurgical assessment of ridge augmentation requirements". International Journal of Periodontics and Restorative Dentistry 16.4 (1996): 322-337.

8. Nyman S., et al. "Bone regeneration adjacent to titanium dental implants using guided tissue regeneration: a report of two cases". The International Journal of Oral and Maxillofacial Implants 5.1 (1990): 9-14.

9. Dahlin C., et al. "Healing of bone defects by guided bone regeneration". Plastic and Reconstructive Surgery 81 (1988): 672676.

10. Herrmann I., et al. "Evaluation of patient and implant characteristics as potential prognostic factors for oral implant failures". The International Journal of Oral and Maxillofacial Implants 20.2 (2005): 220-230.

11. Moy PK., et al. "Dental implant failure rates and associated risk factors". The International Journal of Oral and Maxillofacial Implants 20.4 (2005): 569-577.

12. Aglietta M., et al. "A 10-year retrospective analysis of marginal bone-level changes around implants in periodontally healthy and periodontally compromised tobacco smokers". Clinical Oral Implants Research 22 (2011): 47-53.

13. Bengazi F., et al. "Recession of the soft tissue margin at oral implants. A 2-year longitudinal prospective study". Clinical Oral Implants Research 7.4 (1996): 303-310.

14. Park SY., et al. "Long-term outcomes of adjacent and antagonistic teeth after implant restoration: a focus on patient-related factors". Journal of Periodontal and Implant Science 51.2 (2021): 135-143.
15. Strietzel FP., et al. "Smoking interferes with the prognosis of dental implant treatment: a systematic review and meta-analysis". Journal of Clinical Periodontology 34.6 (2007): 523-544.

16. Schwartz-Arad D., et al. "Failure causes, timing, and cluster behavior: an 8-year study of dental implants". Implant Dentistry 17 (2008): 200-207.

17. Benić GI., et al. "Clinical and radiographic comparison of implants in regenerated or native bone: 5-year results". Clinical Oral Implants Research 20.5 (2009): 507-513.

18. Nevins M., et al. "Implants in regenerated bone: long-term survival". International Journal of Periodontics and Restorative Dentistry 18 (1998): 34-45.

19. Bazrafshan N and Darby I. "Retrospective success and survival rates of dental implants placed with simultaneous bone augmentation in partially edentulous patients". Clinical Oral Implants Research 25.7 (2014): 768-773.

20. Palacios-Garzón N., et al. "Comparison of Marginal Bone Loss Between Implants with Internal and External Connections: A Systematic Review". The International Journal of Oral and Maxillofacial Implants 33.3 (2018): 580-589.

\section{Assets from publication with us}

- Prompt Acknowledgement after receiving the article

- Thorough Double blinded peer review

- Rapid Publication

- Issue of Publication Certificate

- High visibility of your Published work

Website: www.actascientific.com/

Submit Article: www.actascientific.com/submission.php

Email us: editor@actascientific.com

Contact us: +919182824667 